\title{
AVALIAÇÃO DAS PROPRIEDADES FÍSICO-MECÂNICAS DE PAINÉIS AGLOMERADOS DE Eucalyptus grandis COLADOS COM UREIA-FORMALDEÍDO E TANINO-FORMALDEÍDO
}

\author{
Rafael Rodolfo de Melo ${ }^{1}$, Elio José Santini ${ }^{2}$, Clóvis Roberto Haselein ${ }^{2}$, Diego Martins Stangerlin ${ }^{1}$, \\ Marcos Theodoro Muller ${ }^{3}$, Cláudio Henrique Soares Del Menezzi ${ }^{4}$ \\ ${ }^{1}$ Eng. Florestal, Doutorando em Ciências Florestais, UnB, Brasília, DF, Brasil - rrmelo2@ yahoo.com.br - \\ diego_stangerlin@yahoo.com.br \\ ${ }^{2}$ Eng. Florestal, Dr., Depto. de Ciências Florestais, UFSM, Santa Maria, RS, Brasil - elio.santini@pq.cnpq.br, clovis.haselein@smail.ufsm.br \\ ${ }^{3}$ Eng. Civil, M.Sc., UFSM, Santa Maria, RS, Brasil - marcosthemuller@msn.com \\ ${ }^{4}$ Eng. Florestal, Dr., Depto. Eng. Florestal, UnB, Brasília, DF, Brasil - cmenezzi@unb.br \\ Recebido para publicação: 15/02/2009 - Aceito para publicação: 25/09/2009
}

\begin{abstract}
Resumo
Foram avaliadas as propriedades físico-mecânicas de painéis aglomerados confeccionados com partículas de Eucalyptus grandis e colados com as resinas ureia-formaldeído e tanino-formaldeído de Acacia mearnsii. As chapas foram produzidas com massa específica nominal de 0,60 e $0,70 \mathrm{~g} / \mathrm{cm}^{3}$. Para avaliar as características das chapas produzidas no estudo, foram determinadas as propriedades físicas (massa específica, teor de umidade, absorção de água e inchamento em espessura após 2 e 24 horas) e a resistência mecânica (flexão estática, ligação interna e resistência ao arrancamento de parafusos). Os resultados obtidos indicaram que painéis que utilizaram a resina tanino-formaldeído como aglutinante obtiveram maior estabilidade dimensional e resistência mecânica. A resistência mecânica também foi influenciada positivamente com o aumento da massa específica.

Palavras-chave: Painéis reconstituídos; propriedades físico-mecânicas; tanino-formaldeído e ureiaformaldeído.
\end{abstract}

\begin{abstract}
Physical-mechanical properties evaluation of the Eucalyptus grandis particleboard glued with ureaformaldehyde and tannin-formaldehyde. The objective of this work was to evaluate the Eucalyptus grandis particleboards agglutinate with urea-formaldehyde and tannin-formaldehyde of Acacia mearnsii resin. In order to characterize the particleboards quality, the physical properties (density, moisture content, water absorption, and thickness swelling after 2 and 24 hours) and mechanical resistance (static bending, internal bonding, and screw withdrawal) were determined. Results showed that particleboards manufactured with tannin-formaldehyde resin presented a higher quality. The mechanical resistance was also positively influenced by the density increase.

Keywords: Particleboards; physical-mechanical properties; tannin-formaldehyde and ureaformaldehyde.
\end{abstract}

\section{INTRODUÇÃO}

O Brasil apresenta uma área de aproximadamente 5,74 milhões de hectares de florestas plantadas, sendo 3,55 milhões (pouco mais de 61\%) com espécies do gênero Eucalyptus (MELO et al., 2008). Espécies desse gênero apresentam alta adaptabilidade às condições edafoclimáticas brasileiras, o que refletiu diretamente em sua produtividade e, por conseguinte, no volume de áreas plantadas. As espécies mais plantadas/utilizadas no país são o Eucalyptus grandis, o Eucalyptus urophylla e o Eucalyptus viminalis.

Para Haselein (1989), uma das principais dificuldades da utilização da madeira de Eucalyptus na fabricação de painéis de partículas está relacionada à colagem deficiente e absorção excessiva de água. No entanto, diversos pesquisadores vêm demonstrando que há viabilidade na confecção de aglomerados com algumas espécies de Eucalyptus, dentre eles Del Menezzi et al. (1996), Iwakiri et al. (2000) e Cabral 
et al. (2007). Especificamente, Eucalyptus grandis é considerada uma espécie de média densidade, conforme observado por Lopes (2003), para indivíduos com 17 anos. Esse parâmetro proporciona condições adequadas para utilização em painéis aglomerados, o que já vem ocorrendo em escala industrial no país.

Outro importante componente na manufatura dos painéis é o adesivo, com implicações técnicas e econômicas significativas na utilização dos produtos à base de madeira (PIZZI, 1994), com o seu custo podendo chegar até 50\% do preço total do produto com ele confeccionado (CARNEIRO et al., 2004).

Adesivos à base de ureia-formaldeído são muito utilizados nas indústrias de painéis de madeira, principalmente pelo baixo custo, rápida reação em prensa quente e fácil manuseio. Segundo Roffael; Schneider (1983), 90\% de todos os painéis aglomerados produzidos no mundo utilizam esse tipo de resina. A crescente conscientização ambiental e a consequente busca por matérias renováveis vêm paulatinamente impulsionando também a utilização de adesivos à base de tanino vegetal, encontrados na madeira (cerne), casca, raízes, flores, frutos e sementes de algumas espécies arbóreas. Adesivos de tanino já são utilizados industrialmente na África do Sul, Austrália, Zimbábue, Chile, Argentina, Brasil e Nova Zelândia (DUNKY; PIZZI, 2002). George et al. (1976) e Pizzi et al. (1981) expuseram que o tanino-formaldeído apresenta propriedades similares ao fenol-formaldeído. No entanto, junto com o tanino são geralmente extraídos gomas e açúcares que prejudicam a qualidade do adesivo. Uma alternativa para melhorar a qualidade dos adesivos tânicos é modificar os taninos através de hidrólise alcalina ou ácida (PIZZI, 1994).

Hillig et al. (2002) e Calegari et al. (2004) citam que, devido à oscilação dos preços do petróleo e a fragilidade dos produtos sintéticos advindos de fontes de matérias-primas não-renováveis, a utilização de resinas à base de extratos de casca de espécies florestais tem sido alvo de inúmeras investigações. Esses autores destacam ainda que os adesivos à base de tanino, além de serem mais baratos que os adesivos à base de fenol e formol, possuem satisfatória resistência à água.

O objetivo deste trabalho foi avaliar as propriedades físicas e mecânicas de painéis aglomerados produzidos com partículas de Eucalyptus grandis e colados com as resinas ureia-formaldeído e taninoformaldeído.

\section{MATERIAL E MÉTODOS}

\section{Preparo e obtenção das partículas}

Para a realização deste trabalho, foram utilizadas partículas da madeira de Eucalyptus grandis W. Hill ex Maiden, obtidas de árvores de povoamentos florestais homogêneos de aproximadamente 15 anos, localizados no campus da Universidade Federal de Santa Maria, na cidade de Santa Maria, RS. Depois de desdobradas, as árvores foram resserradas com cortes perpendiculares à grã, para obtenção de blocos de $5 \times 7 \mathrm{~cm}$ (tangencial x longitudinal) e largura variável (radial), conforme o diâmetro e posição de obtenção das tábuas na tora, os quais foram imersos em água até a saturação, exceto algumas amostras, que foram levadas à câmara de climatização para determinação da massa específica aparente da madeira (12\% de umidade). Os valores de massa específica da madeira foram utilizados posteriormente para o cálculo da taxa de compressão das chapas (razão entre a massa específica do painel e a massa específica da madeira, ambas a $12 \%$ de umidade).

Posteriormente, dos blocos de madeira saturados foram obtidas lascas em moinho de facas (flaker) com corte ajustado para 0,55 mm de espessura, produzindo, assim, lascas com 50 x $70 \mathrm{x}$ $0,55 \mathrm{~mm}$. As lascas foram secas e reduzidas a partículas em moinho de martelos equipado com peneira com orifícios de $8,0 \mathrm{~mm}$ de diâmetro. As partículas produzidas foram selecionadas em peneira de malha $1,0 \times 1,0 \mathrm{~mm}$, sendo aproveitadas as que não passaram pela malha (Figura 1).

\section{Adesivos utilizados}

No estudo, foram utilizados os adesivos ureia-formaldeído (UF) e tanino-formaldeído (TF). No caso da UF, foi empregada uma resina produzida industrialmente, contendo aproximadamente $65 \%$ de sólidos. Para produção do TF, foi utilizado o tanino condensado extraído de acácia-negra (Acacia mearnsii De Wild.), o qual foi diluído a 50\% em água, onde permaneceu por 24 horas, para atingir a total hidratação do tanino. Posteriormente, foi adicionada soda cáustica, até que o $\mathrm{pH} 8$ fosse atingido. $\mathrm{O}$ formaldeído foi adicionado apenas no momento da aplicação, sendo utilizado em 10\% do teor de sólido da resina produzida. 


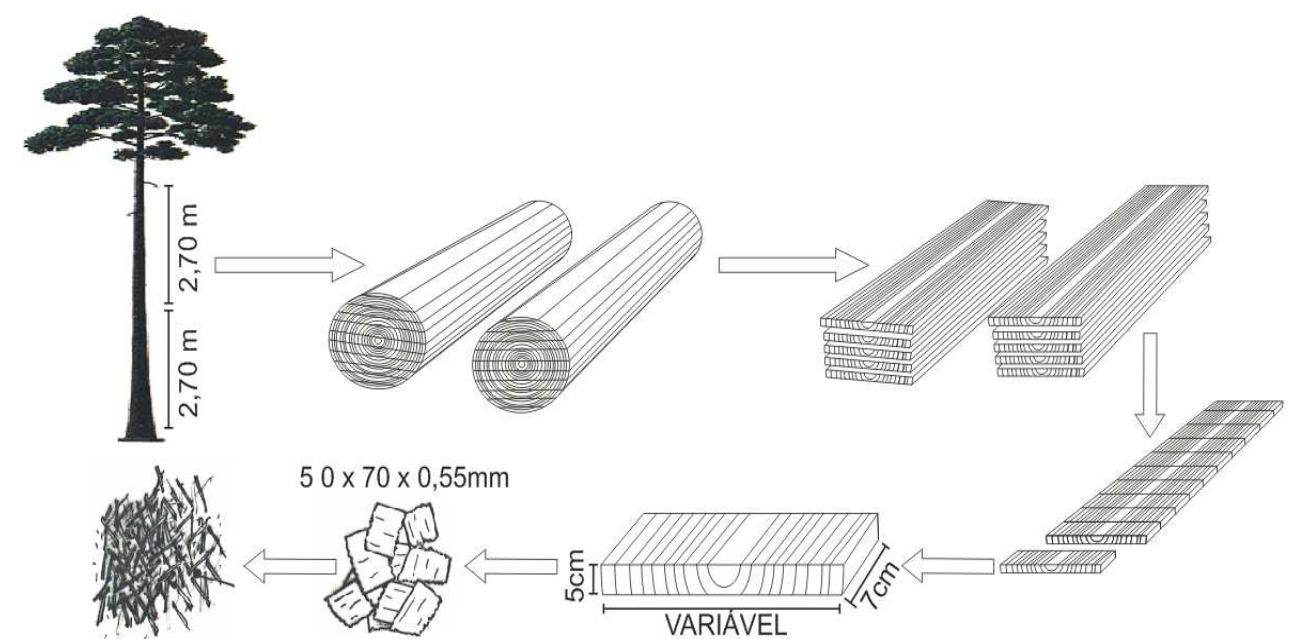

Figura 1. Sequência do processamento para obtenção das partículas de Eucalyptus grandis utilizadas na confecção dos painéis.

Figure 1. Sequence of the processing for obtaintion Eucalyptus grandis particles used for board confection.

\section{Produção dos painéis e confecção das amostras}

Foram produzidos painéis com massa específica nominal preestabelecida em 0,60 e $0,70 \mathrm{~g} / \mathrm{cm}^{3}$ para cada tipo de resina, nas dimensões 50 × 50 x $0,95 \mathrm{~cm}$. O adesivo $(8 \%$ de sólidos com base no peso seco das partículas) e a parafina em forma líquida (1\% de sólidos com base no peso seco das partículas) foram aplicados por meio de pistola acionada por compressor de ar em um tambor rotativo. Juntamente com eles, foi aplicada a água necessária para ajustar o teor de umidade do colchão para aproximadamente $12 \%$ para ureia-formaldeído e $20 \%$ para tanino-formaldeído. Esse elevado teor de umidade do colchão para painéis confeccionados com adesivo à base de tanino é resultado das recomendações de Hillig et al. (2002), que observaram melhores propriedades físico-mecânicas em chapas produzidas com esse teor de umidade.

Gerada a massa do colchão, foi retirada uma pequena amostra de $50 \mathrm{~g}$ para a determinação do teor de umidade desse colchão, e quando esta apresentava uma variação superior a $\pm 2 \%$ da estimada, o material era descartado e o processo repetido. Em seguida, a massa de partículas foi levada a um molde de madeira, com as dimensões $50 \times 50 \times 20 \mathrm{~cm}$, onde foi prensada manualmente. Após isso, foi feita a prensagem definitiva em prensa hidráulica, com a temperatura de $180{ }^{\circ} \mathrm{C}$, com pressão de $30 \mathrm{kgf} / \mathrm{cm}^{2}$. O tempo de fechamento da prensa foi de 40 segundos, e o tempo total de prensagem aplicado para promover a evaporação da água e a cura do adesivo foi de 8 minutos para painéis produzidos com UF e de 10 minutos para painéis produzidos com TF. Após a confecção, os painéis foram dispostos em câmara climatizada $\left(20 \pm 3{ }^{\circ} \mathrm{C}\right.$ e $65 \pm 1 \%$ de umidade relativa) até atingirem massa constante. Em seguida, foram retiradas as amostras para os ensaios, conforme ilustrado na figura 2.

\section{Avaliação dos resultados}

Para avaliação das propriedades das chapas produzidas, foram realizados ensaios físicos (teor de umidade, massa específica, absorção d'água, inchamento em espessura) e mecânicos (flexão estática, arrancamento de parafusos e ligação interna), adotando-se as recomendações da norma da American Society for Testing and Materials - ASTM D 1037 (1998). Os valores médios observados para as propriedades mecânicas foram comparados com os mínimos exigidos pela norma de comercialização americana da American National Standards Institute - ANSI 208.1 (1993). Para o inchamento em espessura, conforme sugerido por Carneiro et al. (2004), os valores foram comparados com os exigidos pela norma do German Standards Committee - DIN 68761(1)-1961(3) (1971), uma vez que a norma ANSI não contempla essa especificação. 
Os dados obtidos foram avaliados por meio de análise de variância com posterior comparação das médias pelo teste Tukey $(\mathrm{p}<0,05)$. Para auxiliar na análise dos resultados, foram realizadas ainda análises de correlações simples entre as variáveis.

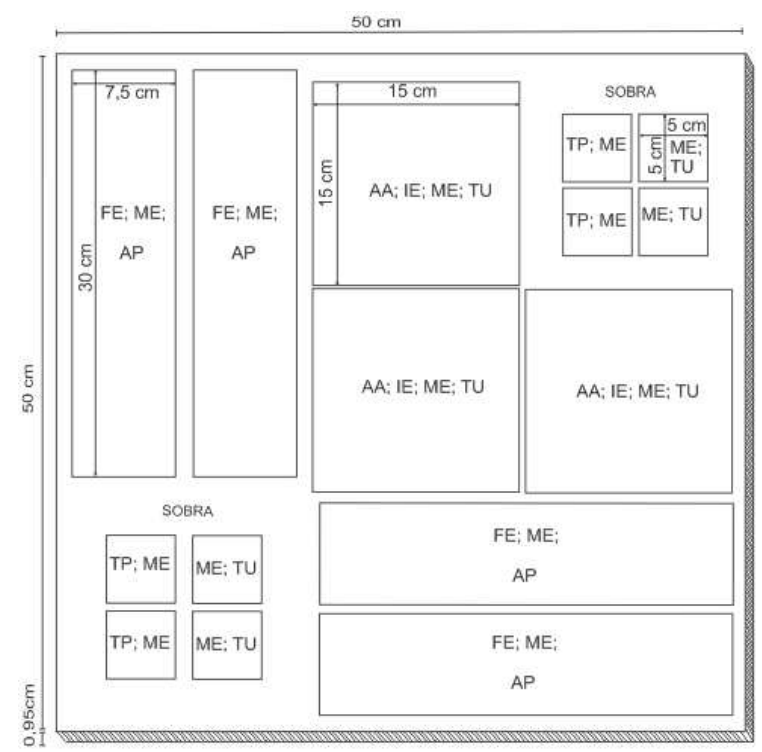

Figura 2. Modelo de corte das chapas para a confecção dos corpos de prova ( $\mathrm{FE}=$ flexão estática; $\mathrm{ME}=$ massa específica; $\mathrm{TU}=$ teor de umidade; $\mathrm{AP}=$ arrancamento de parafusos; $\mathrm{AA}=$ absorção de água; $\mathrm{IE}=$ inchamento em espessura; $\mathrm{TP}=$ tração perpendicular à superfície do painel).

Figure 2. Cut model for confection of the board ( $\mathrm{FE}=$ static bending; $\mathrm{ME}=$ density; $\mathrm{TU}=$ moisture content; $\mathrm{AP}=$ screw withdrawal; $\mathrm{AA}=$ water absorption; $\mathrm{IE}=$ thickness swelling; $\mathrm{TP}=$ internal bond).

\section{RESULTADOS E DISCUSSÃO}

\section{Propriedades físicas}

Na tabela 1, podem ser observados os valores médios de massa específica dos painéis após climatização e da taxa de compressão. A massa específica encontrada para a madeira de Eucalyptus grandis foi de $0,51 \pm 0,04 \mathrm{~g} / \mathrm{cm}^{3}$. Observa-se que, para a massa específica dos painéis, os valores encontrados foram relativamente próximos aos preestabelecidos pela massa específica nominal, que fora de 0,60 para T1 e T3 e de 0,70 para T2 e T4. Segundo Hillig (2000) e Dacosta (2004), essas pequenas variações ocorrem no processo manual de manufatura dos painéis em laboratório, especialmente nas fases de montagem do colchão e/ou na adição de resinas e outros aditivos.

Tabela 1. Valores médios de massa específica nominal e observada (MEn e MEo) e taxa de compressão nominal e observada (TXCn e TXCo) para os diferentes tratamentos avaliados.

Table 1. Average values of estimated and observed density (MEn and MEo) and compression rate estimated and observed (TXCn and TXCo) for different treatments.

\begin{tabular}{lccccc}
\hline Tratamento & Adesivo & MEn $\left(\mathbf{g} / \mathbf{c m}^{\mathbf{3}}\right)$ & MEo $\left(\mathbf{g} / \mathbf{c m}^{\mathbf{3}}\right)$ & TXCn & TXCo \\
\hline T1 & Ureia-Formaldeído & 0,60 & $0,61(0,02) \mathrm{b}$ & 1,18 & $1,20(0,04) \mathrm{b}$ \\
T2 & Ureia-Formaldeído & 0,70 & $0,72(0,04) \mathrm{a}$ & 1,37 & $1,41(0,07) \mathrm{a}$ \\
T3 & Tanino-Formaldeído & 0,60 & $0,61(0,03) \mathrm{b}$ & 1,18 & $1,20(0,06) \mathrm{b}$ \\
T4 & Tanino-Formaldeído & 0,70 & $0,71(0,04) \mathrm{a}$ & 1,37 & $1,40(0,07) \mathrm{a}$ \\
\hline
\end{tabular}

Médias seguidas por uma mesma letra em cada coluna não diferem estatisticamente (Tukey, $p \geq 0,05$ ). Valores entre parênteses representam o desvio padrão.

A taxa de compactação também apresentou resultado bem próximo ao estimado. Hillig et al. (2002) menciona que esse é um parâmetro muito importante na predição das propriedades dos painéis. O 
autor afirma ainda que, de forma geral, todas as propriedades físico-mecânicas das chapas, em maior ou menor intensidade, são afetadas pela razão de compactação, e que taxas de compactação muito baixas não produzem bom contato entre as partículas, prejudicando a colagem e a resistência da chapa.

Os valores médios do teor de umidade do colchão e de equilíbrio dos painéis podem ser observados na tabela 2. Para o teor de umidade do colchão, para os painéis colados com UF e preestabelecidos em $12 \%$, os valores variaram ente 11,29 e $11,67 \%$. Já os painéis que utilizaram o TF como aglutinante, que tinham esse parâmetro preestabelecido em $20 \%$, apresentaram variação média entre 18,65 e $19,84 \%$. Para todos os casos, os resultados foram menores que os desejados. Isso se deve, provavelmente, às pequenas parcelas dos produtos aplicados (água, adesivo e parafina) que são perdidas por aderirem aos instrumentos (mangueira, pistola e tambor rotativo). Para o teor de umidade de equilíbrio (TUeq) alcançado pelas chapas após climatização, não foi verificada a existência de diferença estatística significativa entre as médias dos tratamentos, o que dá maior confiabilidade aos resultados, já que o teor de umidade do painel pode influenciar significativamente suas propriedades (HASELEIN et al., 2002).

Tabela 2. Valores médios de teor de umidade do colchão nominal e observados (TUCn e TUCo) e teor de umidade de equilíbro (TUeq) atingido pelos painéis.

Table 2. Average values estimated and observed of moisture content (TUCn and TUCo) and equilibrium moisture content (TUeq) by the boards reached.

\begin{tabular}{lcccc}
\hline Tratamento & Adesivo & TUCn $(\%)$ & TUCo $(\%)$ & TUeq $(\%)$ \\
\hline T1 & Ureia-Formaldeído & 12,00 & $11,29(0,35)$ b & $8,38(0,26)$ a \\
T2 & Ureia-Formaldeído & 12,00 & $11,67(0,28)$ b & $8,27(0,20)$ a \\
T3 & Tanino-Formaldeído & 20,00 & $18,65(0,58)$ a & $8,70(0,29)$ a \\
T4 & Tanino-Formaldeído & 20,00 & $19,84(0,62)$ a & $8,58(0,30)$ a \\
\hline
\end{tabular}

Médias seguidas por uma mesma letra em cada coluna não diferem estatisticamente (Tukey, $p \geq 0,05$ ). Valores entre parênteses representam o desvio padrão.

Os valores médios de absorção de água e inchamento em espessura após 2 e 24 horas são apresentados na tabela 3. Observa-se que às duas horas a variação da massa específica dos painéis e do tipo do adesivo não influenciou a absorção de água pelos painéis. Esses resultados diferem dos obtidos por Okino et al. (1997), que, ao estudarem a influência de adesivos à base de ureia-formaldeído e taninoparaformaldeído, verificaram, após duas horas de imersão em água, que painéis confeccionados com UF apresentaram maior absorção de água. Entretanto, a UF é reconhecidamente um adesivo de considerável resistência à umidade quando submetida a um rápido contato. Para 24 horas, o aumento da densidade média dos painéis de 0,60 para $0,70 \mathrm{~g} / \mathrm{cm}^{2}$ não proporcionou variações significativas na absorção de água. Já a variação entre adesivos indicou que painéis que utilizaram TF obtiveram menores valores de absorção. Em estudos realizados por Fernandes et al. (2003), os autores também observaram que painéis produzidos com tanino de Acacia mearnsii apresentaram resultados satisfatórios quanto a esse parâmetro.

Tabela 3. Comparações entre médias de absorção de água (AA) e inchamento em espessura (IE), às 2 e 24, para os diferentes tratamentos avaliados.

Table 3. Comparison of average between water absorption (AA) and thickness swelling (IE), 2 and 24 hours, for different treatments.

\begin{tabular}{lcccc}
\hline Tratamento & AA2 $(\boldsymbol{\%})$ & AA24 $(\boldsymbol{\%})$ & IE2 $(\boldsymbol{\%})$ & IE24 $(\boldsymbol{\%})$ \\
\hline T1 & $11,52(2,07) \mathrm{a}$ & $40,82(7,01) \mathrm{a}$ & $9,42(1,54) \mathrm{a}$ & $32,37(5,18) \mathrm{a}$ \\
T2 & $10,23(2,34) \mathrm{a}$ & $39,01(4,23) \mathrm{a}$ & $7,94(1,23) \mathrm{b}$ & $29,14(3,73) \mathrm{a}$ \\
T3 & $12,97(3,91) \mathrm{a}$ & $32,28(4,70) \mathrm{b}$ & $7,50(2,06) \mathrm{b}$ & $22,17(3,71) \mathrm{b}$ \\
T4 & $11,55(2,05) \mathrm{a}$ & $30,41(2,23) \mathrm{b}$ & $7,08(2,71) \mathrm{b}$ & $21,55(3,06) \mathrm{b}$ \\
\hline
\end{tabular}

Médias seguidas por uma mesma letra em cada coluna não diferem estatisticamente (Tukey, $p \geq 0,05$ ). Valores entre parênteses representam o desvio padrão.

Para o inchamento em espessura após 2 horas, T1 foi o que apresentou a maior instabilidade dimensional após 2 horas de exposição. Nos demais tratamentos não houve diferença significativa. Após $24 \mathrm{~h}$ de imersão em água, chapas confeccionadas com UF (T1 e T2) apresentaram inchamento em espessura superior às observadas com as confeccionadas com TF (T3 e T4). Esse comportamento pode 
ser atribuído ao fato de que os taninos são ricos em fenóis e polifenóis e, quando misturados ao formaldeído, produzem reconhecidamente adesivos com boa resistência à umidade (PIZZI et al., 1981). Gonçalves et al. (2008) também verificaram que a adição parcial de tanino ao adesivo UF proporcionou significativa melhoria na estabilidade dimensional das chapas.

Caneiro et al. (2004), ao estudarem chapas de flocos de Eucalyptus grandis e Pinus elliottii, coladas com diferentes composições de ureia-formaldeído e tanino obtidos das espécies Eucalyptus grandis e Eucalyptus pellita, verificaram que painéis confeccionados com ureia-formaldeído obtiveram maior estabilidade dimensional. Isso indica que, embora adesivos confeccionados com tanino possam apresentar considerável resistência à umidade, a qualidade desses adesivos e de sua adesão depende muito de sua formulação, do material de origem e de tratamentos realizados para melhoria de sua eficiência.

Mesmo os tratamentos de maior estabilidade dimensional (T3 e T4) obtiveram valores de inchamento superiores aos exigidos pela norma DIN 68761(1)-1961(3), que estabelece como inchamento máximo 12\% (fenol) ou 15\% (ureia) às 24 horas (GERMAN STANDARDS COMMITEE, 1971). Resultados semelhantes foram observados por Hillig (2000) para chapas de flocos confeccionadas com $8 \%$ de TF. Haselein et al. (2002) obtiveram resultados de 56,75 e 27,43\% de absorção de água e inchamento em espessura, respectivamente, às 24 horas, com chapas de aglomerados de Pinus elliottii fabricadas com $8 \%$ de resina à base de tanino de acácia-negra e com $1 \%$ de parafina.

A massa específica foi o parâmetro que apresentou o maior número de correlações com as variáveis que caracterizam a estabilidade dimensional das chapas, sendo observada correlação não significativa apenas para o IE24 (Tabela 4). Esse resultado pode ser explicado em parte pela liberação das tensões geradas durante a prensagem (spring back), que acelera a absorção de água e consequentemente o inchamento em espessura (SUCHSLAND, 1973). Outras correlações significativas foram observadas entre $\mathrm{Ab} 2^{\mathrm{x}} \mathrm{Ab} 24$, IE $2^{\mathrm{x}} \mathrm{IE} 24, \mathrm{Ab} 24^{\mathrm{x}} \mathrm{IE} 24$ e IE $2^{\mathrm{x}} \mathrm{Ab} 24$. Dacosta (2004) observou, para painéis produzidos com resíduos de madeira e colados com UF, redução da absorção de água com o aumento da massa específica. Já para o inchamento em espessura foi observado comportamento inverso.

Tabela 4. Correlações entre os valores de absorção de água (AA) e inchamento em espessura (IE) às 2 e 24 horas, e a massa específica dos painéis (MEo).

Table 4. Correlation between water absorption (AA) and thickness swelling (IE) in 2 and 24 hours, and observed density of the boards (MEo).

\begin{tabular}{lcccc}
\hline & AA2 & AA24 & IE2 & IE24 \\
\hline MEo & $-0,42^{* *}$ & $-0,39 * *$ & $-0,36^{*}$ & $-0,15^{\mathrm{NS}}$ \\
Ab2 & & $0,49 * *$ & $0,22^{\mathrm{NS}}$ & $0,05^{\mathrm{NS}}$ \\
Ab24 & & $0,44^{* *}$ & $0,70^{* *}$ \\
IE2 & & & $0,61^{* *}$ \\
\hline
\end{tabular}

** e *: significativo a 1 e a $5 \%$; ${ }^{\text {Ns}}$ : não significativo (Pearson, $\mathrm{p} \leq 0,05$ ).

\section{Resistência mecânica}

Os valores médios observados para os parâmetros que caracterizam a resistência mecânica dos painéis, juntamente com suas respectivas comparações, podem ser observados na tabela 5. Nela, vê-se que, para todas as propriedades avaliadas, a comparação entre médias obteve resultados semelhantes, sendo que T1 apresentou a menor resistência, T2 e T3 apresentaram resultados intermediários, não diferindo estatisticamente, e T4 apresentou as maiores resistências. Isso indica que o aumento da massa específica dos painéis, para ambas as resinas utilizadas, proporcionou valores significativamente superiores de resistência. Resultados semelhantes foram observados por Iwakiri et al. (2008) para painéis de Pinus spp.

Quanto a comparações entre adesivos, para painéis com uma mesma massa específica, foi observado que o tanino-formaldeído proporcionou chapas de maior resistência mecânica, quando comparado à ureia-formaldeído, o que indica que painéis produzidos com resina alternativa à base de tanino podem gerar chapas de madeira aglomerada com elevadas propriedades mecânicas, conforme mencionado por Roffael; Dix (1994). Carneiro et al. (2004), ao estudarem a composição de chapas de flocos com taninos extraídos da casca de Eucalyptus grandis e Eucalyptus pellita, verificaram que a combinação dos adesivos tânicos de eucalipto com os adesivos à base de ureia-formaldeído ocasionou aumento em algumas das propriedades mecânicas estudadas. Diferente disso, Gonçalves et al. (2003) observaram, para painéis aglomerados de Eucalyptus pellita colados com ureia-formaldeído e adição parcial de extrato tânico (Mimosa caesalpiniaefolia), que o único parâmetro de resistência que aumentou 
significativamente com a adição do tanino foi a ligação interna. Já Gonçalves et al. (2008) verificaram que a adição parcial de tanino no adesivo UF não promoveu aumento da resistência dos painéis para nenhum dos ensaios realizados.

Tabela 5. Comparações entre médias do módulo de elasticidade (MOE), módulo de ruptura (MOR), resistência ao arrancamento de parafusos (AP) e ligação interna (LI).

Table 5. Comparison of average between modulus of elasticity (MOE), modulus of rupture (MOR), screw withdrawal test (AP) and internal bond (LI).

\begin{tabular}{lcccc}
\hline Tratamento & MOE $(\mathbf{M P a})$ & MOR $(\mathbf{M P a})$ & AP $(\mathbf{N})$ & LI $(\mathbf{M P a})$ \\
\hline T1 & $1.329,49(151,84) \mathrm{c}$ & $12,92(1,82) \mathrm{c}$ & $721,97(88,49) \mathrm{c}$ & $0,16(0,02) \mathrm{c}$ \\
T2 & $1.667,45(251,63) \mathrm{b}$ & $16,53(2,60) \mathrm{b}$ & $829,77(85,95) \mathrm{b}$ & $0,20(0,03) \mathrm{b}$ \\
T3 & $1.625,00(181,73) \mathrm{b}$ & $16,75(1,71) \mathrm{b}$ & $791,64(74,58) \mathrm{b}$ & $0,21(0,03) \mathrm{b}$ \\
T4 & $1.962,04(296,33) \mathrm{a}$ & $19,28(2,80) \mathrm{a}$ & $945,11(83,89) \mathrm{a}$ & $0,26(0,03) \mathrm{a}$ \\
\hline
\end{tabular}

Médias seguidas por uma mesma letra em cada coluna não diferem estatisticamente (Tukey, p $\geq 0,05$ ). Valores entre parênteses representam o desvio padrão.

A norma de comercialização ANSI 208.1 (1993) considera como valores mínimos para painéis de média densidade 1.700 e 11 MPa para o MOE e MOR, respectivamente. Logo, observa-se que apenas o T4 apresentou valor superior ao estipulado pela norma para o MOE. Para o MOR, todos os tratamentos atingiram o mínimo requerido. A mesma norma define ainda para AP e LI os valores mínimos de $1.000 \mathrm{~N}$ e $0,20 \mathrm{MPa}$, respectivamente. Para o AP, nenhum dos tratamentos avaliados alcançou em valor médio essas exigências. Quanto à LI, apenas T1 não obteve resultado satisfatório.

Na tabela 6, podem ser observadas as correlações existentes entre testes mecânicos realizados e a massa específica dos painéis. Para todos os parâmetros, foram evidenciadas correlações significativas, sendo a maior delas para a relação entre o MOE e o MOR $(r=0,74)$. A relação entre essas variáveis geralmente segue esse padrão e, segundo Kelly (1977), deve-se à influência que diversas variáveis de processamento exercem de forma similar tanto no MOE como no MOR.

Tabela 6. Correlações entre os módulos de elasticidade e ruptura (MOE e MOR), resistência ao arrancamento de parafusos (AP), ligação interna (LI) e a massa específica dos painéis (MEo).

Table 6. Correlation between modulus of elasticity and rupture (MOE and MOR), screw withdrawal test (AP), internal bond (LI) and observed density of the boards.

\begin{tabular}{lcccc}
\hline & MOE & MOR & AP & LI \\
\hline MEo & $0,67^{* *}$ & $0,69^{* *}$ & $0,65^{* *}$ & $0,76^{* *}$ \\
MOE & & $0,74^{* *}$ & $0,55^{* *}$ & - \\
MOR & & & $0,48^{* *}$ & - \\
\hline
\end{tabular}

**: significativo a $1 \% ;{ }^{\text {NS }}$ : não significativo (Pearson, $\mathrm{p} \leq 0,05$ ).

Observa-se também que a massa específica influenciou positivamente a resistência dos painéis, o que está de acordo com o observado por Iwakiri et al. (2008). A influência da massa específica sobre as propriedades mecânicas dos painéis aglomerados pode ser atribuída à razão de compactação das partículas que constituem o colchão. Maloney (1993) afirma que, quanto maior a massa específica do painel, maior será a quantidade de partículas e, consequentemente, maior também será a compactação do material durante a prensagem e conformação do painel.

Conforme mencionado por Gonçalves et al. (2008), geralmente, ao ser extraído, o tanino pode apresentar adicionalmente em sua composição gomas, açúcares e outras substâncias não-adesivas, as quais prejudicam a qualidade do adesivo e consequentemente a de sua adesão. Apesar disso, para todos os ensaios físico-mecânicos realizados, painéis produzidos com TF apresentaram valores médios estatisticamente diferentes e superiores, quando comparados àqueles que utilizaram a UF como aglutinante.

\section{CONCLUSÕES}

- Os painéis produzidos com a resina alternativa à base de tanino-formaldeído proporcionaram qualidade superior aos confeccionados com ureia-formaldeído, tanto para estabilidade dimensional como para a resistência mecânica. 
- O aumento da densidade nominal dos painéis produzidos, de 0,60 para $0,70 \mathrm{~g} / \mathrm{cm}^{3}$, resultou em incremento significativamente superior na resistência mecânica dos painéis.

- Pode-se concluir, também, que os adesivos produzidos a partir do tanino de Acacia mearnsii apresentam potencialidade em seu uso, já que, para os testes realizados, painéis produzidos com esse adesivo demonstraram valores médios superiores aos da resina comercial ureia-formaldeído.

\section{AGRADECIMENTOS}

À Sociedade Extrativa Tanino de Acácia (SETA S.A.), pela doação do tanino utilizado na produção da resina tanino-formaldeído $(\mathrm{TF})$.

\section{REFERÊNCIAS}

AMERICAN NATIONAL STANDARDS INSTITUTE. ANSI-A-208.1-87. Mat-formed wood particleboard. Gaithersburg: National Particleboards Association, 1993. 9 p.

AMERICAN SOCIETY FOR TESTING AND MATERIALS. ASTM D-1037. Standard test methods for evaluating properties of wood-based fiber and particle panel materials. In: ANNUAL Book of ASTM Standards. Philadelphia, 1998. v. 04.09.

CABRAL, C. P.; VITAL, B. R.; DELlA LUCIA, R. M.; PIMENTA, A. S. Propriedades de chapas de aglomerado confeccionadas com misturas de partículas de Eucalyptus spp. e Pinus elliottii. Revista Árvore, Viçosa, MG, v. 31, n. 5, p. 897-905, 2007.

CALEGARI, L.; HASElEIN, C. R.; BARROS, M. V.; SCARAVELlI, T. L.; DACOSTA, L. P.; PEDRAZZI, C.; HILLIG, E. Adição de aparas de papel reciclável na fabricação de chapas de madeira aglomerada. Ciência Florestal, Santa Maria, v. 14, n. 1, p. 193-204, 2004.

CARNEIRO, A. C. O.; VITAL, B. R.; PIMENTA, A. S.; DELLA LUCIA, R. M. Propriedades de chapas de flocos fabricadas com adesivo de ureia-formaldeído e de taninos de casca de Eucalyptus grandis W. Hill ex Maiden ou de Eucalyptus pellita F. Muell. Revista Árvore, Viçosa, MG, v. 28, n. 5, p. 715-724, 2004.

DACOSTA, L. P. E. Utilização de resíduos do processamento mecânico da madeira para a fabricação de chapas aglomeradas. 118 p. Dissertação (Mestrado em Engenharia Florestal) Universidade Federal de Santa Maria, Santa Maria, 2004.

DEL MENEZZI, C. H. S.; SOUZA, M. R.; GONÇALVES, J. C. Fabricação e avaliação tecnológica da chapa aglomerada de mistura de Eucalyptus urophyllai T. S. Blake e Pinus oocorpa Schiede. Revista Árvore, Viçosa, MG, v. 20, n. 3, p. 371-379, 1996.

DUNKY, M.; PIZZI A. Wood adhesives. In: Chaudhury, M. and Pocius, A.V. (Eds.), Adhesive Science and Engineering.Elsevier: Amsterdam, 2002. p. 1039-1103.

FERNANDES, M. M.; LELIS, R. C. C.; TOSTES, A. S.; BRITO, E. O. Avaliação da qualidade de chapas de partículas manufaturadas com resina tanino-formaldeído. Floresta e Ambiente, Seropédica, v. 10, n. 02, p. 100-104, 2003.

GEORGE, J.; ZOOLAGUD, S. S.; RANGARAJU, T. S. Preliminary investigations on the use of tannin adhesives for particle board manufacture. IPIRI Journal, v. 6, n. 1, p. 37-41, 1976.

GERMAN STANDARDS COMMITTEE. DIN 68761 (1)-1961 (3). Deutschen Normanausschuss. Specifications for particleboards. Holtz, 1971.

GONÇALVES, C. A.; LELIS, R. C. C.; BRITO, E. O.; NASCIMENTO, A. M. Produção de chapas de madeira aglomerada com adesivo uréia-formaldeído modificado com tanino de Mimosa caesalpiniaefolia Bentham (sabiá). Floresta e Ambiente, Seropédica, v. 10, n. 1, p. 18-26, 2003. 
GONÇALVES, F. G.; LELIS, R. C. C.; OLIVEIRA, J. T. Influência da composição da resina taninouréia-formaldeído nas propriedades físicas e mecânicas de chapas aglomeradas. Revista Árvore, Viçosa, MG, v. 32, n. 04, 715-722, 2008.

HASELEIN, C. R. Análise de parâmetros para a fabricação de chapas de partículas aglomeradas de madeira de eucalipto (Eucaliptus grandis W. Hill ex Maiden) e embaúva (Cecropia sp.). 75 p. Dissertação (Mestrado em Ciência Florestal), Universidade Federal de Viçosa, Viçosa, MG, 1989.

HASElEIN, C. R.; CALEGARI, L.; BARROS, M. V.; HACK, C.; HILlIG, E.; PAULESKI, D. T.; POZZERA, F. Resistência mecânica e à umidade de painéis aglomerados com partículas de madeira de diferentes dimensões. Ciência Florestal, Santa Maria, v. 12, n. 2, p. 127-134, 2002.

HILLIG, E. Qualidade de chapas aglomeradas estruturais, fabricadas com madeiras de Pinus, Eucalipto e Acácia negra, puras ou misturadas, coladas com tanino-formaldeido. 96 p. Dissertação (Mestrado em Engenharia Florestal) - Universidade Federal de Santa Maria, Santa Maria, 2000.

HILLIG, E.; HASELEIN, C. R.; SANTINI, E. J. Propriedades mecânicas de chapas aglomeradas estruturais fabricadas com madeiras de pinus, eucalipto e acácia-negra. Ciência Florestal, Santa Maria, v. 12, n. 1, p. 59-70, 2002.

IWAKIRI, S.; STINGHEN, A. B. M.; SILVEIRA, E. L.; ZAMARIAN, E. H. C.; PRATA, J. G.; BRONOSKI, M. Influência da massa específica sobre as propriedades mecânicas de painéis aglomerados. Floresta, Curitiba, v. 38, n. 03, p. 487-493, 2008.

IWAKIRI, S.; CRUZ, C. R.; OLANDOSKI, D. P.; BRAND, M. A. Utilização de resíduos de serraria na produção de chapas de madeira aglomerada de Eucalyptus saligna, Eucalyptus citriodora e Eucalyptus pilularis. Floresta e Ambiente, Seropédica, v. 7, n. 1, p. 251-256, 2000.

KELLY, M. W. Critical literature review of relationships between processing and physical properties of particleboard. Madison: USDA Forest Service,1977. $66 \mathrm{p}$.

LOPES, M. C. Agrupamento de árvores matrizes de Eucalyptus grandis em função das variáveis dendrométricas e das características tecnológicas da madeira. $93 \mathrm{p}$ Dissertação (Mestrado em Engenharia Florestal) - Universidade Federal de Santa Maria, Santa Maria, RS, 2003.

MALONEY, T. M. Modern particleboard \& dry-process fiberboard. San Francisco: Miller Freeman, 1993. $681 \mathrm{p}$.

MELO, R. R.; STANGERLIN, D. M.; MÜLLER, M. T.; TREVISAN, R.; GATTO, D. A.; SANTINI, E. J.; HASELEIN, C. R. Evolução do setor florestal brasileiro. In: SIMPÓSIO LATINO-AMERICANO SOBRE MANEJO FLORESTAL, 4., 2008, Santa Maria. Anais... Santa Maria: UFSM/CCR/Programa de Pós-Graduação em Engenharia Florestal, 2008. p. 223-229.

OKINO, E. Y. A.; ANDAHUR, J. P. V.; SANTANA, M. A. E.; SOUZA, M. R. Resistência físico mecânica de chapas aglomeradas de bagaço de cana-de-açúcar modificado quimicamente. Scientia Forestalis, Piracicaba, n. 52, p. 35-42, 1997.

PIZZI, A. (Ed.) Advanced wood adhesives technology. New York: M. Dekker, 1994. 289 p.

PIZZI, A.; SCHARFETTER, H.; KES, E. W. Adhesives and techniques open new possibilities for the wood processing industry. 1. Experience with tannin based adhesives. Holz Roh-Werks, v. 39, n. 6, p. $85-89,1981$.

ROFFAEL, E.; DIX, B. Tannine als Bindemittel für Holzwerkstoffe. Holz-Zentralblatt, Leinfelden, v. 120, n. 6, p. 90-93, 1994.

ROFFAEL, E.; SCHNEIDER, A. Untersuchungen über den Einflub von Kochsalz als Bindemittelzusatz auf Eigenschaften von Spanplatten. Holz-Zentralblatt, Leinfelden, v. 109, n. 103, p. 1414-1415, 1983.

SILVA, J. C. Eucalipto: a madeira do futuro. Revista da madeira, Curitiba, Ed. especial, 2001, p. 114.

SUCHSLAND, O. Higroscopic thickness swelling and related properties of selected commercial particleboard. Forest Products Journal, Madison v. 23, n. 7, p. 26-30, 1973. 
